\title{
Treatment of primary cutaneous apocrine carcinoma of the scalp - case and review of the literature
}

\author{
Zachary M Brown', Maria C Riesco-Martinez ${ }^{2}$ and Teresa Petrella ${ }^{1 *}$ \\ ${ }^{1}$ Odette Cancer Centre, Sunnybrook Health Sciences Centre, Canada \\ ${ }^{2}$ Department of Medical Oncology Hospital Universitario 12 de Octubre, Canada
}

\begin{abstract}
Primary cutaneous apocrine carcinoma (PCAC) of the scalp is a rare type of sweat gland neoplasm, with pathological features that make it difficult to distinguish from metastatic breast cancer. Review of the literature reports only 17 similar cases, which are reviewed based on the treatment used and survival outcomes. A 42 year old woman with such a case is described to supplement available literature. The patient described presented with a $3 \times 2 \mathrm{~cm}$ mass on the scalp and was treatment surgically with no additional adjuvant treatment due to limited literature suggesting substantial benefits of adjuvant chemotherapy or radiation for these neoplasms.
\end{abstract}

\section{Introduction}

Primary cutaneous apocrine carcinoma (PCAC) is a rare type of sweat gland neoplasm with incidence rates estimated to range from 0.0049-0.0173 per 100,000 patients per year [1]. Approximately 200 total cases are reported in the literature. PCAC occurs in areas with large numbers of apocrine glands [2]. The scalp is among one of the rarest sites of occurrence, while the axilla appears most commonly [3]. Among the 186 cases reviewed by Hollowell, equal distribution was present in both males and females, with $76 \%$ of the sample population of Caucasian ethnicity. Median age was calculated at 67 years for this sample, which is the largest cohort studied to date [1].

PCAC can develop in the dermal and subcutaneous layers of the skin, occasionally infiltrating the epidermal layer resulting in ulceration. PCAC has a diverse presentation, occurring as both uniand multi-nodular growths with varying colour [2]. Often these neoplasms are indurated, painless masses and can be associated with benign lesions [2], including a nevus sebaceous, most commonly seen with scalp lesions [4-6]. Development of these lesions typically occurs within a year before diagnosis [7]; however several cases have reported longer durations with a period of rapid growth $[4,5,8,9]$. PCAC is often quite difficult to differentiate from metastases of adenocarcinoma of the breast, for two reasons: First PCAC has a morphological profile almost indistinguishable from that of metastatic carcinoma of the breast [10], which may be attributed to the fact that the mammary glands are defined as a form of modified sweat gland [11]. Secondly, no immunohistochemical profile has been developed to differentiate between the two that have been widely agreed upon. This often leaves the diagnosis to be determined by clinical history and a thorough examination in search of a primary site [10].

Of the approximate 200 cases of PCAC, very few cases have reported detailed accounts of scalp primaries. We report the case of a 42 year-old woman who presented with a $3 \times 2 \mathrm{~cm}$ mass on the scalp treated with surgery and review reported cases in the literature on the prognosis, treatment and outcomes of PCAC.

\section{Case report}

A previously healthy 42 year-old woman presented at her family doctor after her hairdresser noticed a nodule in the left temporo-parietal area of the scalp. The mass was a firm, reddish nodule measuring approximately $3 \times 2 \mathrm{~cm}$. The patient was completely asymptomatic. She was referred to dermatology, and the lesion was excised. The initial pathology report showed a moderately-well differentiated adenocarcinoma. It was unclear at this time whether this was a primary lesion of the sweat gland or metastatic adenocarcinoma from another site. She was then referred to our centre for oncologic work-up.

The pathology was reviewed and confirmed a moderately differentiated adenocarcinoma (Figure 1). The tumour was formed by single tubules or complex back to back tubular structures with areas where the luminal cells showed apical snouts. The lesion filled the reticular dermis without involving the epidermis. No perineural or lymphovascular invasion was present. The resection margins were clear, with the closest margin at $2 \mathrm{~mm}$. The immunohistochemistry showed positivity for $\mathrm{CK} 7, \mathrm{ER}, \mathrm{PR}$, Androgen receptor, CDX2, Ber ep4 and EMA. It was found to be negative for High molecular weight keratin, CK 20, COX2, CDX2, TTF1, Renal cell marker, CD 117, and CEA. It was concluded that this profile was most consistent with a metastatic breast carcinoma; however an eccrine/apocrine carcinoma of the skin could not be completely ruled out.

On physical examination, there was no palpable lymphadenopathy of the neck, supraclavicular or infraclavicular regions bilaterally. No pre- or postauricular lymphadenopathy. On the left temporal parietal scalp, there was a $3 \mathrm{~cm}$, well-healed scar, with no signs of infection or

Correspondence to: Dr. Teresa Petrella, Odette Cancer Centre, Sunnybrook Health Sciences Centre, 2075 Bayview Ave., M4N 3M5, Toronto, ON, Canada, Tel: (416) 480 5248; E-mail: teresa.petrella@sunnybrook.ca

Key words: apocrine carcinoma, sweat gland, breast, scalp, treatment

Received: June 15, 2016; Accepted: July 19, 2016; Published: July 22, 2016 
recurrence. No other suspicious skin lesions of the scalp, face or neck were found. The breast exam didn't show any nodules or masses, no suspicious skin lesions and no axillary lymphadenopathy. The rest of the exam was unremarkable. Bilateral mammograms and bilateral breast MRI were conducted and showed no evidence of malignancy. CT scan of the head and neck didn't show any evidence of pathologic lymph nodes or masses. Staging with CT scan of chest, abdomen and pelvis was also negative for metastatic disease.

Her case and pathology was further reviewed at the multidisciplinary case rounds and it was concluded that with the histopathological features and absence of a breast primary carcinoma this was considered a primary apocrine carcinoma of the scalp. The patient had an adequate excision initially and no further excision was done. It was felt that there was not enough evidence to treat the area with adjuvant radiation and patient remained on surveillance. The patient is currently on surveillance and remains free of disease 39 months post surgery.

\section{Literature review results}

We conducted a literature review to assess treatment options for patients with PCAC of the scalp. Our review identified 17 cases which had detailed reports, with the first four cases documented by Domingo and Helwig in 1979 [5]. Of the 17 reported cases, 10 females (58.8\%) and 7 males (41.2\%) made up the cohort. Race was only reported in 3 of the manuscripts. The mean age of the cohort at time of diagnosis was 57.8 years with a range from 20 to 85 years of age.

Of the 17 cases in our review, 12 manuscripts provided information regarding disease status upon presentation (standardized staging is not defined for this population). Ten cases (58.8\%) had reported locally defined neoplasms, with no report of malignancy in the lymph nodes, while 2 cases $(11.8 \%)$ had reported node positive disease (Table 1). Metastatic disease was not present at diagnosis in any of the reported cases and staging was not defined in 5 of the cases [12].

The size of the scalp masses varied among the cohort, with maximal measurements ranging from 0.5 to $7.5 \mathrm{~cm}$, with an average of $3.1 \mathrm{~cm}$. There were 7 non-metastatic lesions, all of which were $4 \mathrm{~cm}$ or less, with an average length of $2.2 \mathrm{~cm}$ at presentation. Average size of the metastatic lesions was $5.9 \mathrm{~cm}$, with 4 of the 6 measuring $4 \mathrm{~cm}$ and greater and 2 unreported (Table 2).

The PCAC of the scalp exhibited variable growth patterns among the 9 cases that had reported these details. Several cases reported long periods of evolution associated with benign lesions, often from birth, followed by a short period of rapid growth of the tumour mass [4-6]. Other cases demonstrated more spontaneous development from a range of several weeks to 6 months $[12,13]$. Due to limited information

Table 1. Details of disease progression at diagnosis, as well as recurrence and metastases of 17 case reports.

\begin{tabular}{|c|c|c|}
\hline Status & n $(N=17)$ & Percentage $(\%)$ \\
\hline \multicolumn{3}{|c|}{ At Diagnosis } \\
\hline Local Disease & 10 & $58.8 \%$ \\
\hline Node Positive & 2 & $11.8 \%$ \\
\hline Metastatic Disease* & 0 & $0.0 \%$ \\
\hline Not Reported & 5 & $29.4 \%$ \\
\hline \multicolumn{3}{|c|}{ Recurrence/Metastases Outcome } \\
\hline No Recurrence & 4 & $23.5 \%$ \\
\hline Local/Regional Recurrence & 3 & $17.6 \%$ \\
\hline Metastatic Disease* & 6 & $35.3 \%$ \\
\hline Not Reported & 4 & $23.5 \%$ \\
\hline
\end{tabular}

*Excludes lymph node metastases alone however, statistical analysis of these patterns in relation to prognosis could not be determined with accuracy.

Standard primary treatment among PCAC lesions of the scalp appears to be surgical excision, occurring in all but one of the cases analysed (94.1\%) (Table 3). In one instance, 6 palliative chemotherapy cycles were implemented instead due to initial misdiagnosis. Despite this, the patient showed excellent response and was disease free for 7 years following treatment [14]. For localized masses the most common surgical intervention was local excision (of undefined margins), as seen in $87.5 \%$ of the surgical treatments. Those with local excision had from 4 months of disease remission to six years with no evidence of disease (Table 2). Radical or wide excision (with $2 \mathrm{~cm}$ margins) of the scalp lesion and regional lymph node dissection, were used in the presence of regional disease on two accounts $(12.5 \%)$ [3,15]. The patient who underwent radical excision also received radiation therapy and adjuvant treatment with cisplatin and 5-fluorouracil for node positive disease. Unfortunately this patient had disease progression 10 months following initial treatment. The patient receiving only wide-excision to the scalp and lymph nodes was free of disease for 4 years, at which time disease had spread to the lungs (Table 2).

Information regarding recurrence, disease progression and metastases was available for 14 cases. Among the cohort, 4 cases $(22.2 \%)$ had no disease recurrence, while $3(17.6 \%)$ had shown recurrence to local or regional sites (three involving lymph nodes). Six cases (35.3\%) had developed metastatic disease to lymph nodes, bone, lungs and brain and other cutaneous regions. Information was unreported or patients were lost to follow-up in 4 of the patients (Table 2).

For local recurrences without the involvement of regional lymph nodes, excision of the tumour appears to be sufficient. In the one instance where node negative local recurrence occurred, the patient was free of disease with no evidence of malignancy, at a one year followup [14]. Upon the involvement of regional lymph nodes, such as those in the cervical, preauricular and postauricular regions, the addition of a lymphadectomy along with excision of the primary lesion is common. Surgical intervention alone, following node positive disease provided mixed responses from 2 months to 1 year $[3,5]$. On a separate account, in addition to excision of the primary and lymphadectomy, adjuvant chemotherapy (5-fluorouracil and cisplatin) and radiotherapy were administered and provided the patient with 9 months of disease free status [2].

For the patients that had developed metastatic disease, 5 of the 6 cases provide details regarding further treatment. These included combinations of chemotherapy, radiotherapy and/or surgical intervention. Radiotherapy was commonly used for palliation of both bone and brain metastases (Table 2). Common sites of disease progression occurred in distant lymph nodes (axillary, subclavicular), cutaneous tissue, bone, brain and the lungs. From the time of metastatic diagnosis, survival ranged from approximately one to four years, with an average of 2.25 years $[2,3,5,13,15]$.

Commonly used chemotherapy agents among this cohort included combinations of anthracyclines, taxanes and platinum drugs. Four courses of adriamycin and etoposide with docetaxel proved effective to stabilize lung metastases for 4 years in one patient [15]. Paclitaxel and carboplatin were also used in another patient and administered every 21 days for metastatic disease to bone and lung regions. This patient remained disease free for 16 months [13]. Second line therapies that have been used include the combination of cisplatin and 5-fluorouracil, as well as methotrexate and bleomycin with short lived results $[2,3]$. 
Table 2. Clinical Data of 17 Case Reports of Primary Cutaneous Apocrine Carcinoma of the Scalp.

\begin{tabular}{|c|c|c|c|c|c|c|c|c|}
\hline Reference & Age & Sex & Size $(\mathbf{c m})$ & Time Evolved & $\begin{array}{c}\text { Primary } \\
\text { Treatment }\end{array}$ & $\begin{array}{l}\text { Adenopathy } \\
\text { At Dx }\end{array}$ & Recurrence/Metastases and Treatment & $\begin{array}{c}\text { Outcome } \\
\text { (Follow-up) }\end{array}$ \\
\hline $\begin{array}{l}\text { Domingo \& } \\
\text { Helwig (1979) } \\
{[5]}\end{array}$ & 77 & M & $2 \times 1.2$ & $\begin{array}{l}>17 \text { y } 1.5 \mathrm{~m} \\
\text { growth }\end{array}$ & Excision $\dagger$ & NR & $\begin{array}{l}\text { 1) Cervical LN (6 m) - LN Surgical Removal; 2) LR (1.5y) } \\
- \text { Tx NR }\end{array}$ & $\begin{array}{l}\text { AWD } \\
(1.5 \mathrm{y})\end{array}$ \\
\hline$[5]$ & 63 & $\mathrm{~F}$ & 1.5 & "Birth" & Excision $\dagger$ & NR & No & $\operatorname{NED}(6 \mathrm{y})$ \\
\hline [5] & 68 & $\mathrm{~F}$ & 0.7 & “Unknown” & Excision $\dagger$ & NR & Unknown & LTF \\
\hline [5] & 65 & M & 7 & $\begin{array}{l}\text { "Since birth" } 1 \mathrm{~m} \\
\text { growth }\end{array}$ & $\begin{array}{c}\text { Excision } \dagger \\
\text { (scalp mass) }\end{array}$ & NR & $\begin{array}{l}\text { 1) Post-auricular, cervical and supraclavicular LN (6 m) - } \\
\text { Radiotherapy (neck and supraclavicular LN); 2) Bone Mets. } \\
\text { (9 m)-Radiotherapy }\end{array}$ & DWD $(2 y)$ \\
\hline $\begin{array}{l}\text { Paties } \text { et al. } \\
\text { (1993) [26] }\end{array}$ & 85 & M & 3.5 & $20 \mathrm{y}$ & Excision $\dagger$ & NR & Nucal LN $(2 y)-T x$ NR & $\mathrm{DOC}(2.5 \mathrm{y})$ \\
\hline $\begin{array}{l}\text { Jacyk et al. } \\
\text { (1998) [6] }\end{array}$ & 54 & $\mathrm{~F}$ & $4 \times 1$ & $\begin{array}{l}\text { "Since Childhood" } \\
\text { Few month growth }\end{array}$ & Excision $\dagger$ & No & No & NED (1 y) \\
\hline $\begin{array}{l}\text { Morbabito et al. } \\
\text { (2000) }[2]\end{array}$ & 46 & $\mathrm{~F}$ & NR & NR & Excision $\dagger$ & NR & $\begin{array}{l}\text { 1) LR (temporal) and Cervical LN (4 m) - Radical excision } \\
\text { w/lymphadenectomy, Radiotherapy, Chemo; 2) Cutaneous } \\
\text { Mets. \& Cervical LN (13 m) - Chemotherapy (17 m); 3) } \\
\text { Cutaneous Scalp Lesion Progression }(26 \mathrm{~m}) \text { - Tx NR }\end{array}$ & $\operatorname{DOC}(28 \mathrm{~m})$ \\
\hline $\begin{array}{l}\text { Shimato et al. } \\
\text { (2006) }[15]\end{array}$ & 48 & M & 5 & NR & $\begin{array}{l}\text { Wide excision } \downarrow \\
\text { (scalp and LN) }\end{array}$ & Cervical LN & $\begin{array}{l}\text { 1) Lung Mets. (4y) - Chemotherapy; 2) Brain Mets. (6y) } \\
\text { - Excision and Radiotherapy; 3) Brain recurrence (7y) - } \\
\text { Excision; 4) Lung Mets. Progression (8y) }\end{array}$ & DWD (8 y) \\
\hline $\begin{array}{l}\text { Robson et al. } \\
\text { (2008) [12] }\end{array}$ & 73 & $\mathrm{~F}$ & 0.5 & NR & $\begin{array}{l}\text { Complete Local } \\
\text { Excision } \dagger\end{array}$ & NR & No & $\begin{array}{l}\text { NED (LTF } \\
2.5 \mathrm{y})\end{array}$ \\
\hline$[12]$ & 63 & $\mathrm{~F}$ & 2.4 & NR & $\begin{array}{l}\text { Complete Local } \\
\text { Excision } \dagger\end{array}$ & NR & NR & LTF \\
\hline [12] & 70 & $\mathrm{~F}$ & 1.9 & NR & $\begin{array}{l}\text { Complete Local } \\
\text { Excision } \dagger\end{array}$ & NR & No & $\operatorname{NED}(2.5 \mathrm{y})$ \\
\hline [12] & 43 & $\mathrm{~F}$ & 7.5 & $6 \mathrm{~m}$ & $\begin{array}{l}\text { Complete Local } \\
\text { Excision } \dagger\end{array}$ & NR & $\begin{array}{l}\text { Metastases* (noted possible chemotherapy - individual } \\
\text { cases not detailed) }\end{array}$ & DWD (6 y) \\
\hline [12] & 31 & M & 1.4 & $3 \mathrm{~m}$ & $\begin{array}{c}\text { Complete Local } \\
\text { Excision } \dagger\end{array}$ & NR & NR & LTF \\
\hline $\begin{array}{l}\text { Tlemcani et al. } \\
\text { (2010) [13] }\end{array}$ & 20 & M & NR & "Several Weeks" & Excision $\dagger$ & NR & $\begin{array}{l}\text { LR, LN, Bone and Lung Mets. }(16 \mathrm{~m})-\text { Palliative } \\
\text { Radiotherapy and Chemotherapy }\end{array}$ & $\operatorname{DWD}(55 \mathrm{~m})$ \\
\hline $\begin{array}{l}\text { Kim et al. (2011) } \\
{[14]}\end{array}$ & 60 & F & $2 \times 1.5$ & NR & Chemotherapy & NR & LR $(7 \mathrm{y})-$ Wide excision $\ddagger$ & NED $(8 \mathrm{y})$ \\
\hline $\begin{array}{l}\text { Paudel } \text { et al. } \\
\text { (2012) }[4]\end{array}$ & 45 & M & $2 \times 2$ & $\begin{array}{c}\text { "Since Childhood" } \\
4 \text { m growth }\end{array}$ & Excision $\dagger$ & $\begin{array}{c}\text { Cervical } \\
\text { Lymphadenopathy }\end{array}$ & NR & NR \\
\hline $\begin{array}{l}\text { Vucinic et al. } \\
\text { (2012) }[3] \S\end{array}$ & 65 & $\mathrm{~F}$ & 4 & NR & $\begin{array}{l}\text { Radical } \\
\text { Excision } \ddagger \\
\text { (Tumour } \\
\text { and Neck) w/ } \\
\text { Chemo and } \\
\text { Radiotherapy }\end{array}$ & 8/30 Cervical LN & $\begin{array}{l}\text { 1) LR and LN (contralateral cervical) }(10 \mathrm{~m})-\text { Re-excision } \\
\& \text { neck dissection; 2) LR and LN (Cervical \& Axillary) } \\
(12 \mathrm{~m})-\text { Re-excision, neck dissection \& chemo; 3) LN, } \\
\text { Bone, Cutaneous \& Lung Mets. (16 m) - Bisphosphonate \& } \\
\text { Supportive Therapy }\end{array}$ & DWD (3 y) \\
\hline \multicolumn{9}{|c|}{$\begin{array}{l}\text { * Possible Adjuvant Tx - specific case details not provided } \dagger \text { Margins not specified } \ddagger 2 \mathrm{~cm} \text { clear margins } \S \text { Prior history of scalp mass \& enlarged neck LN } 3 \text { years prior (Tx not } \\
\text { reported). } \\
\text { LN - Lymph Node; LR - Local Recurrence; AWD - Alive with Disease; NED - No Evidence of Disease; LTF - Lost to Follow-up; DWD - Died with Disease; DOC - Died of } \\
\text { other causes; NR - Not reported }\end{array}$} \\
\hline
\end{tabular}

\section{Discussion}

PCAC of the scalp is a rare neoplasm most often reported in the literature as case reports or small case series. To date, limited work has been done analyzing the prognosis, outcomes and treatment options available for the various stages of this disease. Concluding our review we were able to identify 17 cases of scalp primaries. Most cases had localized disease at initial presentation, while regional lymph node metastases were less prevalent. Primary treatment is most often local excision of the primary tumour. The use of radiotherapy and chemotherapy are not common outside of palliation, however radiation may be beneficial in treating lymph node metastases. Assessing prognosis is difficult to quantify with accuracy due to limited cases available. Data suggests that localized disease is typically treatable without aggressive therapy; however, survival seems to diminish following lymph node involvement. Data suggests larger primaries at initial visit may also indicate poor prognosis, due to their tendency to metastasize; outcomes are often fatal upon the diagnosis of metastatic disease.
Table 3. Type of primary treatment among 17 cases of PCAC of the scalp.

\begin{tabular}{|l|c|c|}
\hline \multicolumn{1}{|c|}{ Primary Treatment } & $\begin{array}{c}\text { n } \\
(\mathbf{N = 1 7 )}\end{array}$ & Percentage (\%) \\
\hline Surgery & $\mathbf{1 6}$ & $\mathbf{9 4 . 1 \%}$ \\
\hline Local Excision & 14 & $87.5 \%$ \\
\hline Wide Excision* & 1 & $6.3 \%$ \\
\hline Radical Excision* & 1 & $6.3 \%$ \\
\hline Radiotherapy & $\mathbf{1}$ & $\mathbf{5 . 9 \%}$ \\
\hline Chemotherapy & $\mathbf{2}$ & $\mathbf{1 1 . 8 \%}$ \\
\hline
\end{tabular}

$* 2 \mathrm{~cm}$ margins

Our data seems to be consistent with previous demographic and prognostic findings from other PCAC primaries. A review of 186 cases, analysing several PCAC primaries, showed that similar to scalp lesions, patients most often present with localized disease, while metastases to the lymph nodes and distant regions is less common. The data also shows that most cases have a good prognosis with an expected and 
observed 5-year survival of $85.4 \%$ and $76.1 \%$, respectively for all site primaries and overall median survival of 51.5 months. Median survival significantly diminished following lymph node involvement, and metastatic disease, to 33 and 14.5 months, respectively [1]. Conclusions regarding the prognosis among scalp cases are limited due to such a small sample size, however survival seems to correlate with data from these various primaries. In both cases localized disease has shown to be manageable with surgical treatment, however prognosis appears to worsen following the spread of disease into the lymph nodes and other distant regions, often requiring additional treatment.

For the treatment of localized PCAC the current consensus tends to support the use of surgical resection; wide-excision being the recommended procedure. It has been shown that surgical excision provides significant prognostic benefit to patients compared to those who have not undergone surgery [1]. Due to insufficient data, surgical margins have not been standardized, however, 1 to $2 \mathrm{~cm}$ may provide sufficient eradication of tumour cells. These values have been suggested upon validated standards for similar cutaneous lesions [16]. At this point in time there is a lack of evidence to support the use of chemotherapy and radiotherapy in primary treatment of localized disease. Some reports have suggested the use of radiation in the treatment of masses exceeding $5 \mathrm{~cm}$. Due to the aggressive nature of these larger masses seen among scalp cases this recommendation may be warranted, however, it has not been prospectively evaluated [16]. These findings seem to be acceptable for all PCAC of the skin, including the axilla, head and neck and thoracic regions. More delicate regions including the eye or eyelid, and the anogenital region may require more specific treatment regimens.

Due to the significancelymph node involvement has on the prognosis of PCAC, Hollowell has recommended the use of sentinel lymph node biopsy (SLNB) to guide treatment planning [1]. Unfortunately due to the low incidence rate of PCAC, SLNB has not undergone prospective evaluation, but has been shown to provide prognostic value among other cutaneous neoplasms, including melanoma [17], squamous cell carcinoma [18] and merkel cell carcinoma [19]. Although this may suggest SLNB to be useful in this population, treatment should be determined on a case by case basis, as lymph node dissection is not standard practice for PCAC [16].

In patients that present with positive regional lymph nodes, lymphadectomy, in addition to the removal of the primary, is common treatment among the PCAC literature [2,3,15,20-23]. Radiotherapy may also provide additional benefit among those with regional lymph node metastases; however data is limited. Among non-melanocytic skin cancers with lymph node metastases, radiotherapy in addition to surgical excision has also shown to increase survival rates, compared to those who only receive surgery [24,25]. Given the high percentage of metastatic occurrence among PCAC scalp primaries, clinicians should consider the possible benefit of radiotherapy within this population. Chemotherapy should be reserved for treating advanced disease that often proves to be fatal and initiation of palliative care in these circumstances is inevitable [3].

In review of these findings, our patient had a wide excision with no other therapy. Surgical excision has demonstrated to be a standard option for patients with localized disease. In our case, our patient remains disease free at 39 months post surgery. These results are consistent with previous case reports, and may provide interest to those developing treatment plans for similar cases.

\section{Conclusion}

Following an in depth review of the literature on PCAC, it can be concluded that the recommendation for surgical removal with cleared margins seems to be appropriate among patients with local, node negative disease. One to two centimeters surgical margins are generally accepted standards. No evidence is currently available to show the benefit of adjuvant treatment for PCAC.

Patients with additional regional lymph node involvement have lower median survival rates and may benefit from lymphadectomy and additional radiotherapy. Metastases to regional lymph and distant organs appear to be more common among scalp lesions, affecting approximately one third of the scalp cases, thus, suggesting the need for further treatment among this group. The use of chemotherapy and radiotherapy may also be considered in patients with advanced and distant disease, as well as chronic recurrence, but should be decided on a case to case basis.

\section{Disclaimer}

The opinions expressed by authors contributing to manuscript do not necessarily reflect the opinions of the Sunnybrook Health Sciences Centre or the Odette Cancer Centre with which the authors are affiliated.

\section{All authors confirm absence of any conflict of interest.}

The patient discussed in this report has given full consent to the participation and publication of this manuscript.

\section{References}

1. Hollowell KL, Agle SC, Zervos EE, Fitzgerald TL (2012) Cutaneous apocrine adenocarcinoma: defining epidemiology, outcomes, and optimal therapy for a rare neoplasm. J Surg Oncol 105: 415-419. [Crossref]

2. Morabito A, Bevilacqua P, Vitale S, Fanelli M, Gattuso D, et al. (2000) Clinica management of a case of recurrent apocrine gland carcinoma of the scalp: efficacy of a chemotherapy schedule with methotrexate and bleomycin. Tumori 86: 472-474. [Crossref]

3. VuciniÄ† I, Stojadinoviäł T, Mikez ZB, Danï̈ carcinoma of the scalp with aggressive clinical course--a case report and review of the literature. Coll Antropol 36 Suppl 2: 209-212. [Crossref]

4. Paudel U, Jha A, Pokhrel DB, Gurung D, Parajuli S, et al. (2012) Apocrine carcinoma developing in a naevus sebaceous of scalp. Kathmandu Univ Med J (KUMJ) 10: 103105. [Crossref]

5. Domingo J, Helwig EB (1979) Malignant neoplasms associated with nevus sebaceus of Jadassohn. J Am Acad Dermatol 1: 545-556. [Crossref]

6. Jacyk WK, Requena L, Sánchez Yus E, Judd MJ (1998) Tubular apocrine carcinoma arising in a nevus sebaceus of Jadassohn. Am J Dermatopathol 20: 389-392. [Crossref]

7. Miyamoto T, Hagari Y, Inoue S, Watanabe T, Yoshino T (2005) Axillary apocrine carcinoma with benign apocrine tumours: a case report involving a pathological and immunohistochemical study and review of the literature. J Clin Pathol 58: 757-761. [Crossref]

8. Vasilakaki T, Skafida E, Moustou E, Grammatoglou X, Arkoumani E, et al. (2011) Primary cutaneous apocrine carcinoma of sweat glands: a rare case report. Case Rep Oncol 4: 597-601. [Crossref]

9. Katagiri Y, Ansai S (1999) Two cases of cutaneous apocrine ductal carcinoma of the axilla. Case report and review of the literature. Dermatology 199: 332-337. [Crossref]

10. Fernandez-Flores A (2009) The elusive differential diagnosis of cutaneous apocrine adenocarcinoma vs. metastasis: the current role of clinical correlation. Acta Dermatovenerol Alp Pannonica Adriat 18: 141-142. [Crossref]

11. Moore KL, Dalley AF, Agur AMR (2010) Clinically Oriented Anatomy. 6th ed Lippincott Williams and Wilkins, USA.

12. Robson A, Lazar AJ, Ben Nagi J, Hanby A, Grayson W, et al. (2008) Primary cutaneous 
apocrine carcinoma: a clinico-pathologic analysis of 24 cases. Am J Surg Pathol 32: 682-690. [Crossref]

13. Tlemcani K, Levine D, Smith RV, Brandwein-Gensler M, Staffenberg DA, et al. (2010) Metastatic apocrine carcinoma of the scalp: prolonged response to systemic chemotherapy. J Clin Oncol 28: e412-414. [Crossref]

14. Kim HK, Chung KI, Park BY, Bae TH, Kim WS, et al. (2012) Primary apocrine carcinoma of scalp: Report of primary scalp cutaneous apocrine carcinoma indistinguishable from cutaneous metastasis of breast carcinoma. J Plast Reconstr Aesthetic Surg 65: 67-70.

15. Shimato S, Wakabayashi T, Mizuno M, Nakahara N, Hatano H, et al. (2006) Brain metastases from apocrine carcinoma of the scalp: case report. J Neurooncol 77: 285289. [Crossref]

16. Chamberlain RS, Huber K, White JC, Travaglino-Parda R (1999) Apocrine gland carcinoma of the axilla: review of the literature and recommendations for treatment. Am J Clin Oncol 22: 131-135. [Crossref]

17. Wong SL, Balch CM, Hurley P, Agarwala SS, Akhurst TJ, et al. (2012) Sentinel lymph node biopsy for melanoma: American Society of Clinical Oncology and Society of Surgical Oncology joint clinical practice guideline. J Clin Oncol 30: 2912-2918.

18. Fukushima S, Masuguchi S, Igata T, Harada M, Aoi J, et al. (2014) Evaluation of sentinel node biopsy for cutaneous squamous cell carcinoma. $J$ Dermatol 41: 539-541. [Crossref]

19. Warner RE, Quinn MJ, Hruby G, Scolyer RA, Uren RF, et al. (2008) Management of merkel cell carcinoma: the roles of lymphoscintigraphy, sentinel lymph node biopsy and adjuvant radiotherapy. Ann Surg Oncol 15: 2509-2518. [Crossref]

20. Elliott GB, Ramsay DW (1956) Sweat gland carcinoma. Ann Surg 144: 99-106 [Crossref]

21. Kuno Y, Numata T, Kanzaki T (1999) Adenocarcinoma with signet ring cells of the axilla showing apocrine features: a case report. Am J Dermatopathol 21: 37-41. [Crossref]

22. Misago N, Shinoda Y, Okawa T, Aoki S, Toda S, et al. (2011) Histiocytoid and signetring cell carcinoma of the axilla: a type of cutaneous apocrine carcinoma equivalent to histiocytoid lobular carcinoma of the breast? Clin Exp Dermatol 36: 874-877. [Crossref]

23. Terada T, Kamo M, Sugiura M (2013) Apocrine carcinoma of the scrotum with extramammary Paget's disease. Int J Dermatol 52: 504-506. [Crossref]

24. Shimm DS, Wilder RB (1991) Radiation therapy for squamous cell carcinoma of the skin. Am J Clin Oncol 14: 383-386. [Crossref]

25. Veness MJ, Palme CE, Smith M, Cakir B, Morgan GJ, et al. (2003) Cutaneous head and neck squamous cell carcinoma metastatic to cervical lymph nodes (nonparotid): a better outcome with surgery and adjuvant radiotherapy. Laryngoscope 113: 1827-1833. [Crossref]

26. Paties C, Taccagni GL, Papotti M, Valente G, Zangrandi A, et al. (1993) Apocrine carcinoma of the skin. A clinicopathologic, immunocytochemical, and ultrastructural study. Cancer 71: 375-381. [Crossref]

Copyright: (C2016 Brown ZM. This is an open-access article distributed under the terms of the Creative Commons Attribution License, which permits unrestricted use, distribution, and reproduction in any medium, provided the original author and source are credited. 